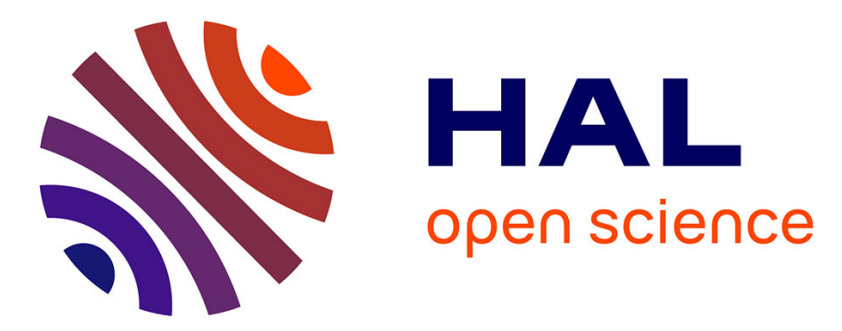

\title{
Highly selective macrocyclic ring-closing metathesis of terminal olefins in non-chlorinated solvents at low dilution
}

\author{
Adrien Dumas, Sophie Colombel-Rouen, Idriss Curbet, Gwenael Forcher, \\ Fabien Tripoteau, Frederic Caijo, Pierre Queval, Mathieu Rouen, Olivier \\ Baslé, Marc Mauduit
}

\section{To cite this version:}

Adrien Dumas, Sophie Colombel-Rouen, Idriss Curbet, Gwenael Forcher, Fabien Tripoteau, et al.. Highly selective macrocyclic ring-closing metathesis of terminal olefins in non-chlorinated solvents at low dilution. Catalysis Science \& Technology, 2019, 9 (2), pp.436-443. 10.1039/c8cy02115e . hal02049520

\section{HAL Id: hal-02049520 \\ https://hal-univ-rennes1.archives-ouvertes.fr/hal-02049520}

Submitted on 22 Mar 2019

HAL is a multi-disciplinary open access archive for the deposit and dissemination of scientific research documents, whether they are published or not. The documents may come from teaching and research institutions in France or abroad, or from public or private research centers.
L'archive ouverte pluridisciplinaire HAL, est destinée au dépôt et à la diffusion de documents scientifiques de niveau recherche, publiés ou non, émanant des établissements d'enseignement et de recherche français ou étrangers, des laboratoires publics ou privés. 


\title{
Highly selective macrocyclic ring-closing metathesis of terminal olefins in non-chlorinated solvents at low dilution
}

\author{
Adrien Dumas, ${ }^{a}$ Sophie Colombel-Rouen, ${ }^{a}$ Idriss Curbet, ${ }^{a}$ Gwénael Forcher, ${ }^{\text {a }}$ Fabien Tripoteau, ${ }^{b}$ \\ Frédéric Caijo, ${ }^{\mathrm{b}}$ Pierre Queval, ${ }^{\mathrm{b}}$ Mathieu Rouen, ${ }^{\mathrm{b}}$ Olivier Baslé ${ }^{\mathrm{a}}$ and Marc Mauduit*a

\begin{abstract}
A set of new ruthenium-indenylidene complexes bearing two unsymmetrical unsaturated $\mathrm{N}$-cycloalkyl-NHC ligands was synthetised. These catalysts proved to be highly selective in the macrocyclic ring-closing metathesis performed in nonchlorinated solvents at low dilution $(0.01 \mathrm{M})$. Without the requirement of benzoquinone derivatives to prevent the isomerisation side reactions, this environmentally friendly catalytic process promoted the synthesis of macrocyclic odorant molecules of remarkable $>99 \%$ purity.
\end{abstract}

\section{Introduction}

Since the development of well-defined, air-stable and easy to handle homogeneous Ru-arylidene complexes in the early $1990 \mathrm{~s},{ }^{1}$ olefin metathesis has become a powerful synthetic tool to efficiently build macrocyclic derivatives, surpassing in most cases traditional ring-closing methodologies such as Wittig reaction, lactonisation or lactamisation. ${ }^{2}$ Advantageously, by limiting drastically the production of wastes, olefin metathesis is also considered as a greener technology. ${ }^{3}$ Numerous macrocyclic products were successfully synthesised through this methodology, ${ }^{4}$ notably macrolactones ${ }^{5 a}$, macrocyclic ketones $^{5 b}$ or carbonates ${ }^{6}$ which are frequently used in perfumery for their strong musk fragrance ${ }^{7}$ (for instance: Ambrettolide (2-one) $1{ }^{8}$ Exaltolide $2,{ }^{9}$ Habanolide ${ }^{\circledR} 3^{10}$ or $(R)$ Muscone ${ }^{\circledR} 4^{11}$; see Figure 1 ). Although significant breakthroughs have been accomplished in the olefin metathesis area during the next decade, thanks to the catalyst design, three major drawbacks remain to be solved to make macrocyclic ringclosing metathesis (RCM) more attractive. ${ }^{12}$

Figure 1. Natural or synthetic macrocyclic derivatives frequently used in perfumery

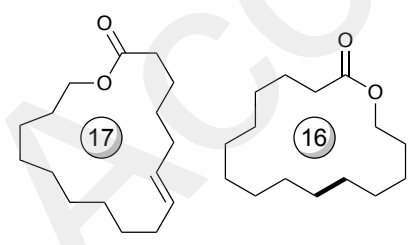

Ambrettolide (2-one) 1
Exaltolide 2

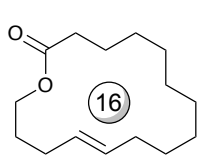

Habanolide ${ }^{\circledR} 3$

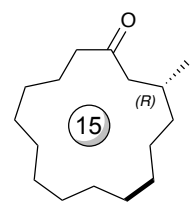

(R)-Muscone ${ }^{\circledR} 4$ a. Univ Rennes, Ecole Nationale Supérieure de Chimie de Rennes, CNRS, ISCR - UMR 6226, F-35000 Rennes, France. E-mail: marc.mauduit@ensc-rennes.fr

b. DEMETA SAS, 6 rue Pierre-Joseph Colin, 35000 Rennes, France

c. Current address : Université du Maine, IMMM - UMR CNRS 6283

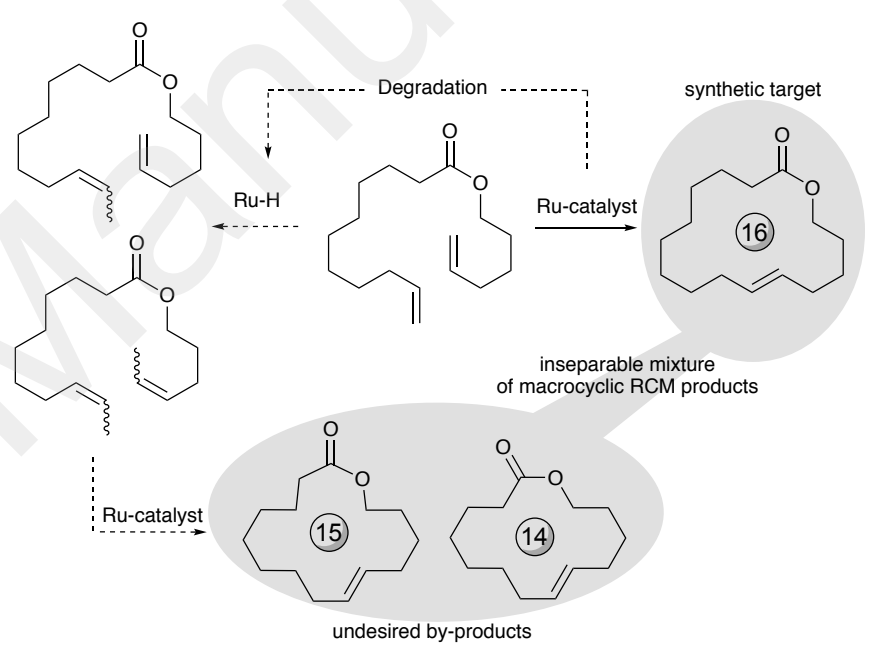

Figure 2. Ring contractions, which occur in macrocyclic ring-closing metathesis

The first one concerns the competitive migration of the terminal double bonds promoted by the presence of hydrido-complexes from the premature decomposition of the Ru-alkylidene species in the media, ${ }^{13}$ leading to the formation of ring contraction byproducts, which are difficult to separate from the targeted macrocycle (Figure 2). Various methods have been considered to inhibit isomerisation with varying degrees of success. ${ }^{14-15}$ The use of toxic chlorinated solvents, ${ }^{14}$ acid additives ${ }^{15 a, b}$ or toxic benzoquinone additives ${ }^{15 a}$ allowed reducing or trapping Ruhydrides to prevent isomerisation during metathesis and afford higher selectivities. Nevertheless, these alternatives are not always efficient and could even appear in contradiction with a so-called environmentally friendly methodology. The second drawback is related to the high catalyst loading (1-5 mol\% typically) often required to achieve attractive yields. ${ }^{12 b, 16}$ Moreover a duality between activity and selectivity is usually observed. For instance, phosphine-based $1^{\text {st }}$ generation Grubbs 
catalyst (Ru-1), have demonstrated remarkable level of selectivity but at the detriment of high catalyst loading to achieve acceptable yields. ${ }^{17}$ In contrast, second generation complexes bearing $N$-heterocyclic carbene (NHC) ligands (Ru-2) gave excellent conversions at lower catalyst loading but the selectivity was seriously altered. ${ }^{18}$ Last but not least, with currently available catalysts, moderate to high dilution conditions (typically 0.5 to $5 \mathrm{mM}$ ) are in most cases required in macrocyclic RCM to minimise self-metathesis and oligomerisation side reactions. ${ }^{5 a, 12 b, 19}$ Obviously, the employment of large volumes of aromatic or chlorinated solvents seriously limits industrial productions, notably for lowvalue products. ${ }^{12 b}$ The quest for an efficient macrocyclic-RCM process involving greener solvents at low dilution/catalyst loading and without the requirement of any toxic additives remains a long-standing goal to chemists. On this concern, we report herein an environmentally friendly and unprecedented highly selective ruthenium-catalysed macrocyclisation of terminal linear olefins in green solvents (ethyl acetate, Me$T H F)^{20}$ at $0.01 \mathrm{M}$ enabling to efficiently produce various macrocyclic odorant molecules of remarkable $>99 \%$ purity.

\section{Experimental}

\section{General information}

All reactions were carried out under an atmosphere of argon using standard Schlenk techniques. Toluene, diethyl ether, dichloromethane and tetrahydrofuran were purified using MBraun Solvent Purification Systems. Ethyl acetate was distilled over calcium hydride. Solvents used for catalysis were freeze-pump-thaw degassed prior to use. All commercial chemicals were used as received unless otherwise noted. The $1 \mathrm{M}$ solution of hydrogen chloride in ethyl acetate was purchased from Acros Organics with AcroSeal packaging. NMR spectra were recorded on a Bruker ARX400 spectrometer $\left({ }^{1} \mathrm{H}(400 \mathrm{MHz})\right.$ and $\left.{ }^{13} \mathrm{C}(101 \mathrm{MHz})\right)$ or Bruker $300\left({ }^{1} \mathrm{H}\right.$ (300 MHz) and ${ }^{13} \mathrm{C}(75 \mathrm{MHz})$ ) with complete proton decoupling for ${ }^{13} \mathrm{C} .{ }^{1} \mathrm{H}$ and ${ }^{13} \mathrm{C}$ chemical shifts are reported in parts per million with the solvent resonance as the internal standard $\left(\mathrm{CDCl}_{3},{ }^{1} \mathrm{H}: \delta 7.26\right.$ ppm, ${ }^{13} \mathrm{C}$ : $\left.\delta 77.16 \mathrm{ppm}\right)$. Coupling constants are reported in Hertz $(\mathrm{Hz})$. Abbreviations are used as follows: $\mathrm{s}=$ singlet, $\mathrm{d}=$ doublet, $\mathrm{t}=$ triplet, $\mathrm{dd}=$ double doublet, $\mathrm{ddt}=$ double double triplet, $\mathrm{dq}=$ double quartet, $\mathrm{td}=$ triple doublet, $\mathrm{q}=$ quartet, $\mathrm{m}=$ multiplet, $\mathrm{br}=$ broad. High Resolution Mass Spectrometry (HRMS) and elemental analysis were performed at the Centre Régional de Mesures Physiques de I'Ouest (CRMPO), Université de Rennes 1.

\section{GC methods}

GC-2014 Shimadzu apparatus. GC column: TR5, 30m x $0.25 \mathrm{~mm} \times 0.25$ $\mu \mathrm{m}$. Injector temperature: $280^{\circ} \mathrm{C}, \mathrm{FID}: 340^{\circ} \mathrm{C}$. Oven temperature: Starting temperature: $100^{\circ} \mathrm{C}$, hold time: 0 minute. Ramp rate $10^{\circ} \mathrm{C} / \mathrm{min}$ to $200^{\circ} \mathrm{C}$, hold time: 10 minutes. Ramp rate $10^{\circ} \mathrm{C} / \mathrm{min}$ to $300^{\circ} \mathrm{C}$, hold time: 2 minutes. Carrier gas: Helium, $\mathrm{u}=40 \mathrm{~cm} / \mathrm{sec}$. Injection volume: $1 \mu \mathrm{l}$. Split ratio: 20:1. Run time: 32 minutes.

\section{Synthesis of complex Ru-11a.}

In a glovebox, to a suspension of imidazolium salt 7a (462 mg, 1.35 mmol, 2.5 equiv.) in dry toluene $(2.7 \mathrm{~mL}$ ) stored in a schlenk was added a $0.5 \mathrm{M}$ solution of potassium bis(trimethylsilyl)amide $(2.7 \mathrm{~mL}$, $1.35 \mathrm{mmol}, 2.5$ equiv.). The mixture was stirred 30 minutes at room temperature. Commercial Ru-3 (500 mg, 0.54 mmol, 1.0 equiv.) was then added in one portion to the schlenk and the resulting solution was allowed to stir at $40^{\circ} \mathrm{C}$ for 2 hours under an argon atmosphere outside the glovebox until TLC analysis showed complete conversion. After evaporation of the solvents, the crude material was purified on $\mathrm{SiO}_{2}$ using the gradient of eluent: pentane/diethyl ether $=90 / 10$ to 70/30. The desired complex Ru-11a was collected as a red solid (253 $\mathrm{mg}, 53 \%$ yield $).{ }^{1} \mathrm{H}$ NMR $\left(400 \mathrm{MHz}, \mathrm{CDCl}_{3}\right) \delta 8.07-7.97(\mathrm{~m}, 1 \mathrm{H}), 7.88$ $-7.81(\mathrm{~m}, 1 \mathrm{H}), 7.75-7.66(\mathrm{~m}, 1 \mathrm{H}), 7.59-7.49(\mathrm{~m}, 1 \mathrm{H}), 7.48-7.36$ $(\mathrm{m}, 3 \mathrm{H}), 7.24-6.99(\mathrm{~m}, 5 \mathrm{H}), 6.92-6.77(\mathrm{~m}, 2 \mathrm{H}), 6.74-6.65(\mathrm{~m}, 2 \mathrm{H})$, $6.43(\mathrm{~s}, 1 \mathrm{H}), 6.31-6.24(\mathrm{~m}, 1 \mathrm{H}), 3.69-3.49(\mathrm{~m}, 1 \mathrm{H}), 2.74-2.60(\mathrm{~m}$, $3 \mathrm{H}), 2.57(\mathrm{~s}, 1 \mathrm{H}), 2.42(\mathrm{~d}, J=5.6 \mathrm{~Hz}, 3 \mathrm{H}), 2.15-1.97(\mathrm{~m}, 5 \mathrm{H}), 1.93-$ $1.82(\mathrm{~m}, 2 \mathrm{H}), 1.76(\mathrm{~d}, J=4.1 \mathrm{~Hz}, 6 \mathrm{H}), 1.68(\mathrm{~s}, 2 \mathrm{H}), 1.55(\mathrm{~s}, 3 \mathrm{H}), 1.50(\mathrm{~s}$, $3 \mathrm{H}), 1.42-1.31(\mathrm{~m}, 2 \mathrm{H}), 1.30-1.16(\mathrm{~m}, 3 \mathrm{H}), 1.10-0.99(\mathrm{~m}, 2 \mathrm{H}) .{ }^{13} \mathrm{C}$ NMR $\left(101 \mathrm{MHz}, \mathrm{CDCl}_{3}\right) \delta 296.2,187.1,144.7,143.3,141.0,140.9$, $140.2,138.1,137.9,137.5,137.2,136.4,136.2,136.1,136.0,135.3$, $129.8,129.3,128.9,128.9,128.3,128.1,128.0,127.4,127.3,127.1$, $126.5,126.1,126.0,125.2,122.9,118.0,117.6,117.5,115.2,62.6$, 59.2, 37.4, 35.3, 35.2, 32.3, 25.9, 24.9, 24.6, 24.1, 23.9, 21.5, 21.0, 20.1, 20.0, 19.4, 18.5, 18.4. HRMS (ESI) calcd. for $\mathrm{C}_{49} \mathrm{H}_{54} \mathrm{~N}_{4}{ }^{35} \mathrm{Cl}_{2}{ }^{102} \mathrm{Ru}$ $[\mathrm{M}]^{+}: \mathrm{m} / \mathrm{z}$ 870.27635, found: 870.2776 (1 ppm). Anal. calcd. for $\mathrm{C}_{49} \mathrm{H}_{54} \mathrm{Cl}_{2} \mathrm{~N}_{4} \mathrm{Ru}: \mathrm{C}, 67.57 \% ; \mathrm{H}, 6.25 \%$;, $6.43 \%$; found: $\mathrm{C}, 67.74 \% ; \mathrm{H}$, $5.93 \% ; \mathrm{N}, 6.04 \%$.

\section{Typical procedure for macrocyclic RCM.}

A stock solution of Ru-11a complex $(8.0 \mathrm{mg})$ in ethyl acetate (1000 $\mu \mathrm{L}$ ) was prepared under argon. A two-necked flask equipped with a reflux condenser and a J Young valve was charged with a solution of diene 5 (133.0 mg, $0.5 \mathrm{mmol}, 1.0$ equiv.) in ethyl acetate $(50 \mathrm{~mL})$. $27.2 \mu \mathrm{L}$ of the freshly prepared stock solution of complex was added. The reaction was initiated upon addition of a $1 \mathrm{M} \mathrm{HCl.EtOAc} \mathrm{solution}$ (12.5 $\mu \mathrm{L}, 0.0125 \mathrm{mmol}, 0.025$ equiv.) and was then placed in an oil bath set at $110^{\circ} \mathrm{C}$ to ensure a reflux for 4 hours. After cooling down to room temperature, the solution was quenched upon addition of ethyl vinyl ether (excess). The crude product was purified by chromatography on silica gel using pentane/diethyl ether $=95 / 5$ as eluent to yield 6 as a pale-yellow oil ( $93 \mathrm{mg}, 78 \%$ yield). >99\% selectivity was found after GC measurement. ${ }^{1} \mathrm{H}$ NMR $(400 \mathrm{MHz}$, $\left.\mathrm{CDCl}_{3}\right) \delta$ (E-isomer) 5.30-5.25 (m, 2H), $4.10(\mathrm{t}, J=7.1 \mathrm{~Hz}, 2 \mathrm{H}), 2.35-$ $2.26(\mathrm{~m}, 2 \mathrm{H}), 2.07-1.97(\mathrm{~m}, 4 \mathrm{H}), 1.67-1.54(\mathrm{~m}, 4 \mathrm{H}), 1.45$ - $1.15(\mathrm{~m}$, 12H). $\delta$ (Z-isomer) 5.42-5.29 (m, 2H), $4.12(\mathrm{t}, J=6.3 \mathrm{~Hz}, 1 \mathrm{H}), 2.35-$ $2.26(\mathrm{~m}, 2 \mathrm{H}), 2.07-1.97(\mathrm{~m}, 4 \mathrm{H}), 1.67-1.54(\mathrm{~m}, 4 \mathrm{H}), 1.45$ - $1.15(\mathrm{~m}$, 12H). $\left.{ }^{13} \mathrm{C} \mathrm{NMR} \mathrm{(101} \mathrm{MHz,} \mathrm{CDCl} 3\right) \delta$ (E-isomer) 174.0, 131.9, 130.4, 64.0, 34.9, 32.1, 32.1, 28.5, 28.4, 28.3, 28.1, 27.3, 26.7, 25.6, 25.3. $\delta$ (Z-isomer) 174.0, 130.2, 129.9, 64.2, 34.0, 29.3, 28.5, 28.3, 28.1, 27.8, $27.3,27.2,26.7,26.6,25.4$. The spectral data for both isomers were identical to those reported in the literature. ${ }^{5 a}$ 
Typical procedure for the hydrogenation of macrocycles.

A round-bottom flask was charged with macrocycle $6(93 \mathrm{mg}, 0.39$ mmol, 1.0 equiv.) and ethyl acetate $(7.8 \mathrm{~mL})$. Palladium on activated carbon (9.8 mg, $0.00975 \mathrm{mmol}, 0.025$ equiv.) was added and a balloon of hydrogen was bubbled in the solution. The resulting mixture was allowed to stir at room temperature under an atmosphere of hydrogen for 16 hours. A balloon of argon was bubbled in the solution, the mixture was filtrated over a short plug of celite and washed with ethyl acetate. The filtrate was concentrated under reduced pressure to yield the reduced macrocycle 2 (Exaltolide) as a white solid. ( $94 \mathrm{mg}, 99 \%$ yield). >99\% selectivity was found after GC measurement. ${ }^{1} \mathrm{H}$ NMR $(400 \mathrm{MHz}$, $\left.\mathrm{CDCl}_{3}\right) \delta 4.12(\mathrm{t}, J=5.7 \mathrm{~Hz}, 2 \mathrm{H}), 2.31(\mathrm{t}, J=6.9 \mathrm{~Hz}, 2 \mathrm{H}), 1.70-1.56(\mathrm{~m}$, $4 \mathrm{H}), 1.45-1.22(\mathrm{~m}, 20 \mathrm{H}) .{ }^{13} \mathrm{C} \mathrm{NMR}\left(101 \mathrm{MHz}, \mathrm{CDCl}_{3}\right) \delta 174.2,64.1$, $34.6,28.5,27.9,27.3,27.2,27.0,26.8,26.5,26.2,26.1,26.0,25.2$, 25.1. The spectral data for this compound were identical to those reported in the literature. ${ }^{5 a}$

\section{Results and discussion}

We started our investigation by evaluating a set of various commercially available Ru-catalysts ${ }^{21}$ (figure 3 and Table 1 ) in the macrocyclic RCM of hex-5-enyl undec-10-enoate 5 performed in ethyl acetate $(0.01 \mathrm{M})$ at $70^{\circ} \mathrm{C}^{22}$ over 4 hours. The resulting RCM macrocycle 6 was isolated in a 80/20 E/Z mixture and then reduced by a standard $\mathrm{Pd} / \mathrm{C}$-catalysed hydrogenation procedure to lead to the expected 16-membered macrocycle 2 (exaltolide) after silica gel purification. ${ }^{5 a}$ Although first generation catalysts (Ru-1 and Ru-3) are known to be less prompt toward isomerisation, they were inefficient in our conditions as only traces of RCM products were detected (entries 1-2). Second generation complexes Ru-2 and Ru-4 gave the expected macrocycle product $\mathbf{2}$ in relatively good yields ( 83 and $79 \%$ respectively, entries $3-4)$. Nevertheless, significant amounts ( 5 and $3 \%$ respectively) of a mixture of 14 - and 15membered macrocycles $\mathbf{C}_{\mathbf{1 4}}$ and $\mathbf{C}_{\mathbf{1 5}}$ were also detected. It is noteworthy that exaltolide $\mathbf{2}$ and related ring-contraction byproducts cannot be separated, even after $\mathrm{SiO}_{2}$ purifications,

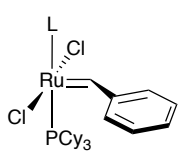

Ru-1 $\left.(\mathrm{L}=\mathrm{PCy})_{3}\right)$

Ru-2 ( $L=$ SIMes)<smiles></smiles>

Ru-7

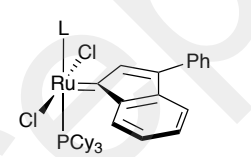

Ru-3 ( $\left.L=P C y_{3}\right)$ Ru-4 ( $\mathrm{L}=\mathrm{SIMes})$

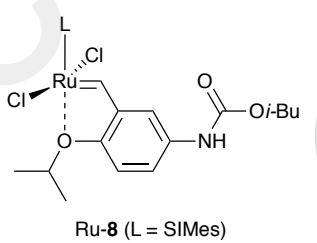

Ru-9 $(\mathrm{L}=\mathrm{SIPr})$

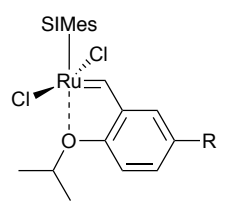

$\mathrm{Ru}-5(\mathrm{R}=\mathrm{H})$ Ru-6 $\left(\mathrm{R}=\mathrm{NO}_{2}\right)$

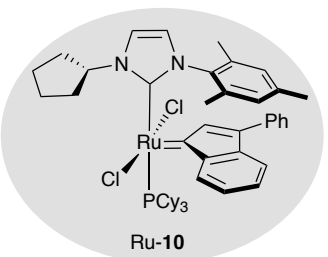

SIMes =
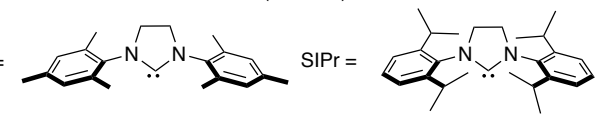

Figure 3. Selected Ru-metathesis complexes used in macrocyclic RCM

as depicted in figure 4 (chromatogram (a)). Unfortunately, similar levels of yields and selectivities were also observed with other commercially available phosphine-free catalysts (entries $5-9)$, even in the case of activated Hoveyda-Grubbs complexes Ru-6 (Grela), Ru-7 (M51) or Ru-8-9 (M73) for which the purity dropped to $67 \%$.

Table 1. Screening of Ru-metathesis complexes Ru-1-10 for the macrocyclic RCM of hex5-enyl undec-10-enoate $\mathbf{5}$ leading to Exaltolide $\mathbf{2}$ after hydrogenation ${ }^{\text {a }}$

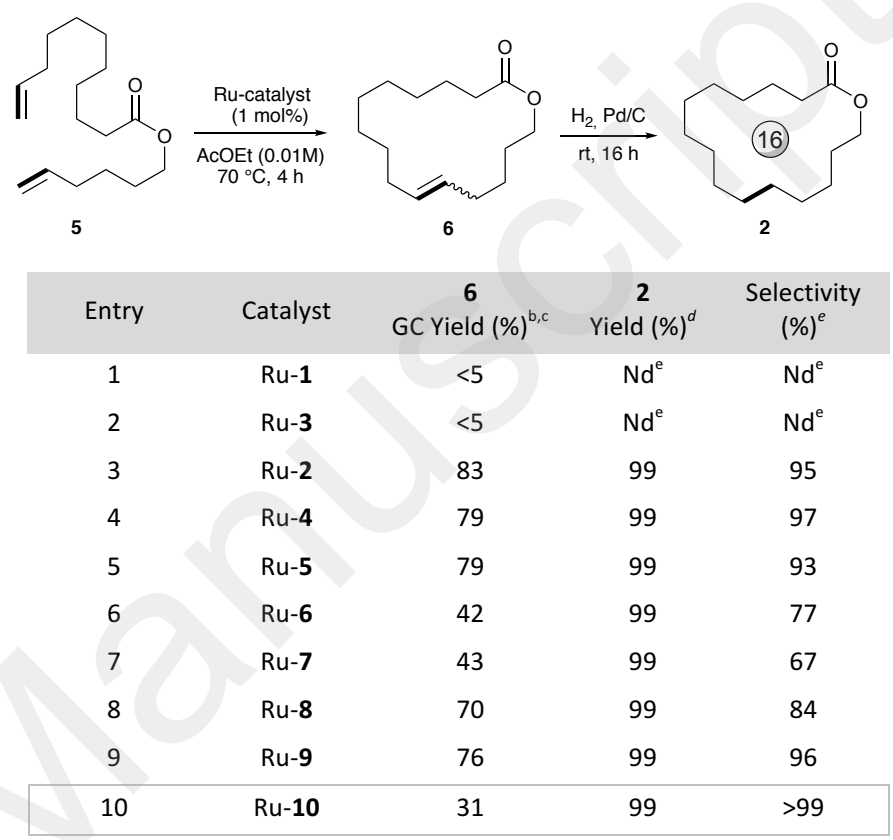

${ }^{a}$ Conditions: (1) Ru-catalyst (1 mol\%), EtOAc (0.01 M), 70 ${ }^{\circ} \mathrm{C}$, 4h. (2) $\mathrm{H}_{2}$ (1 atm), Pd/C $(2.5 \mathrm{~mol} \%), \mathrm{rt}, 16 \mathrm{~h} .{ }^{b}$ Determined by GC analysis with tetradecane as standard (see ESI for details). ${ }^{c}$ E/Z selectivity: $8 / 2$ (determined by GC). ${ }^{d}$ Isolated yields after $\mathrm{SiO}_{2}$ purification. ${ }^{e}$ Determined by GC analysis of $\mathbf{2}$ (see ESI and vide infra, Fig. 4). ${ }^{f}$ Not determined.
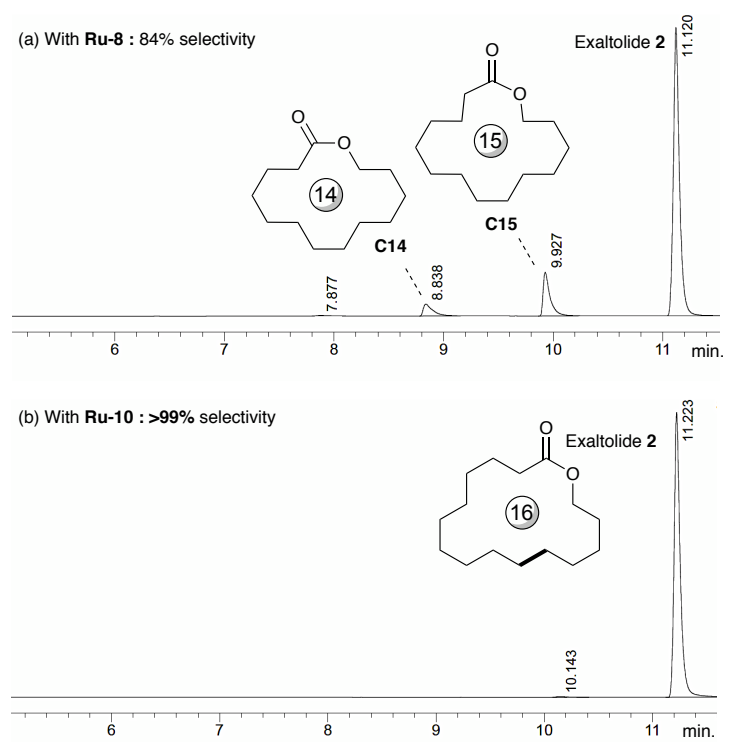

Figure 4. Selectivity of the macrocyclic RCM of $\mathbf{5}$ determined by GC analysis: chromatograms of the $\mathrm{SiO}_{2}$ purified exaltolide 2 obtained with catalyst Ru-8 (a) and with catalyst Ru-10 (b). 
Gratifyingly, we found that the indenylidene-based complex Ru$10^{23}$ bearing an unsymmetrical unsaturated $\left(U_{2}\right)$ cyclopentylIMes NHC ligand was able to afford the desired 16-membered macrocycle with a remarkable $>99 \%$ purity (Figure 4, chromatogram (b)). However, this complex appeared quite unstable under the reaction conditions as a poor $31 \%$ yield was observed (entry 10). Encouraged by this promising result, we decided to develop more robust complexes towards thermic conditions required for macrocyclic-RCM transformations. Indeed, as previously reported by our group, Ru-10 showed a lower thermic stability than SIMes-based parent complexes Ru2 and $\mathrm{Ru}-\mathbf{4}^{24}$
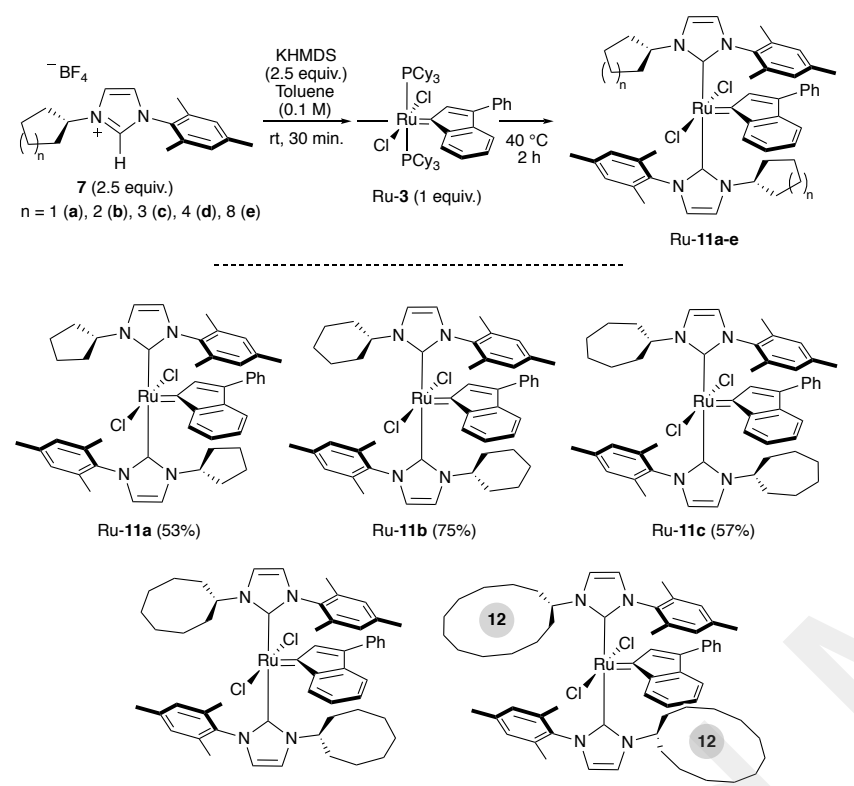

Ru-11d (56\%)

Ru-11e (85\%)

Scheme 1. Synthesis of (cycloalkyl-IMes) ${ }_{2} \mathrm{RuCl}_{2}$ (3-phenylindenylid-1-ene) complexes Ru-11a-e
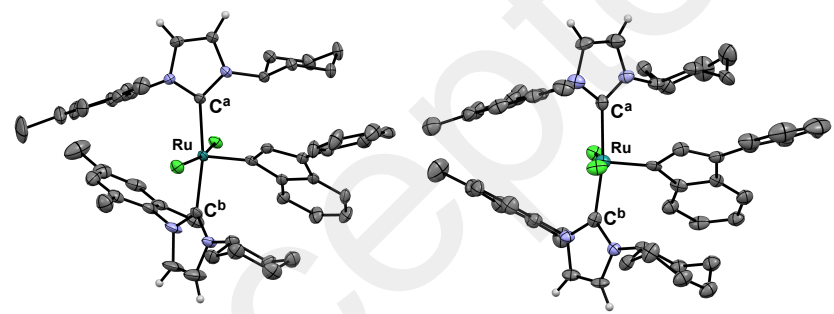

Ru-11b

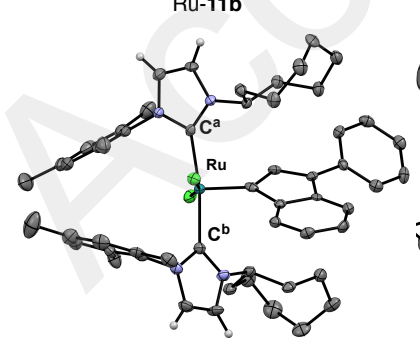

Ru-11d

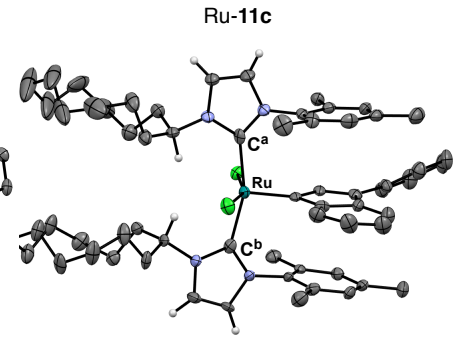

Ru-11e
Figure 5. Solide-state structure of Ru-indenylidene complexes Ru-11b-e from single crystal $\mathrm{X}$-ray diffraction. Hydrogen atoms have been omitted for clarity ( $\mathrm{N}$ in blue, $\mathrm{C}$ in grey, $\mathrm{Cl}$ in green and $\mathrm{Ru}$ in pink).
To tackle this, we focused our attention on Ru-complexes bearing two diaminocarbene units. Indeed, as previously reported by several research groups ${ }^{25}$ and more recently by our group, ${ }^{26}$ bisNHC arylidene complexes have proved to be highly stable at elevated temperature. Therefore, we decided to replace the $\mathrm{PCy}_{3}$ ligand by an additional $\mathrm{U}_{2}-\mathrm{NHC}$ unit. As depicted in Scheme 1, thanks to our recently reported highly modular and straightforward multicomponent synthesis of unsymmetrical NHC precursors $7,{ }^{27}$ a set of five (cycloalkylIMes) ${ }_{2} \mathrm{RuCl}_{2}$ (3-phenylindenylid-1-ene) complexes Ru-11a-e were easily prepared from the commercially available bisphosphine Ru-complex Ru-3 (M1). By employing an excess of imidazolium salt $\mathbf{7}$ in presence of potassium hexamethyldisilazane (KHMDS), pre-catalysts Ru-11a-e were isolated in moderate to good yields (53-85\%). Structures of complexes Ru-11b-e were confirmed by single crystal X-ray diffraction studies, revealing some important structural information (Figure 5, see the ESI for details). ${ }^{28}$ Unfortunately, all attempts to crystallise cyclopentyl-IMes Ru-11a have failed. Having complexes Ru-11a-e in hands, their catalytic behaviours were evaluated in the macrocyclic-RCM of $\mathbf{5}$ under aforementioned standard conditions (Table 2).

Table 2. Screening of Ru-indenylidene complexes Ru-11a-e in the macrocyclic RCM of hex-5-enyl undec-10-enoate $\mathbf{5}$ leading to Exaltolide $\mathbf{2}$ after hydrogenation ${ }^{\text {a }}$
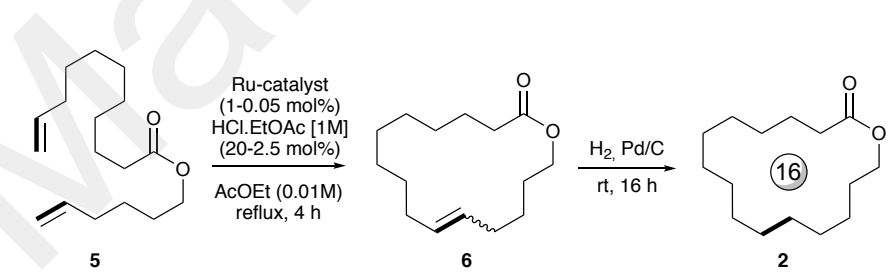

\begin{tabular}{|c|c|c|c|c|c|}
\hline Entry & $\begin{array}{l}\text { Catalyst } \\
\text { (mol\%) }\end{array}$ & $\begin{array}{c}\mathrm{HCl} \text {.EtOAc } \\
{[1 \mathrm{M}]} \\
(\mathrm{mol} \%)\end{array}$ & $\begin{array}{c}6 \quad G C \\
\text { yield }^{c, d} / \text { yield }^{e} \\
(\%)\end{array}$ & $\underset{\text { Yield }(\%)^{f}}{2}$ & $\begin{array}{c}\text { Selectivity } \\
(\%)^{g}\end{array}$ \\
\hline $1^{b}$ & Ru-11a (1) & - & $<5$ & $\mathrm{Nd}^{\mathrm{h}}$ & $\mathrm{Nd}^{\mathrm{h}}$ \\
\hline 2 & Ru-11a (1) & - & 8 & $\mathrm{Nd}^{\mathrm{h}}$ & $\mathrm{Nd}^{\mathrm{h}}$ \\
\hline 3 & Ru-11a (1) & 20 & $88 / 80$ & 99 & $>99$ \\
\hline 4 & Ru-11a (1) & 10 & $90 / 76$ & 99 & $>99$ \\
\hline 5 & $\begin{array}{l}\text { Ru-11a } \\
(0.1)\end{array}$ & 5 & $88 / 76$ & 99 & $>99$ \\
\hline 6 & $\begin{array}{l}\text { Ru-11a } \\
(0.05)\end{array}$ & 2.5 & $90 / 78$ & 99 & $>99$ \\
\hline $7^{i}$ & $\begin{array}{l}\text { Ru-11a } \\
(0.05)\end{array}$ & 2.5 & $76 / 67$ & 99 & $>99$ \\
\hline 8 & Ru-11b (1) & 2.5 & $95 / 72$ & 99 & $>99$ \\
\hline $9^{j}$ & $\mathrm{Ru}-11 \mathrm{c}(1)$ & 2.5 & $93 / 73$ & 99 & $>99$ \\
\hline $10^{\mathrm{j}}$ & $\mathrm{Ru}-11 d(1)$ & 2.5 & $90 / 70$ & 99 & $>99$ \\
\hline 11 & Ru-11e (1) & 2.5 & $93 / 73$ & 99 & $>99$ \\
\hline
\end{tabular}

${ }^{a}$ Conditions: (1) Ru-catalyst (1 to 0.05 mol\%), EtOAc (0.01 M), HCl.EtOAc (1M) (20 to $2.5 \mathrm{~mol} \%$ ), reflux (oil bath set at $\left.110^{\circ} \mathrm{C}\right), 4 \mathrm{~h} .(2) \mathrm{H}_{2}$ (1 atm), $\mathrm{Pd} / \mathrm{C}(2.5 \mathrm{~mol} \%), \mathrm{rt}$, $16 \mathrm{~h}^{b}{ }^{b}$ Metathesis reaction performed at $70^{\circ} \mathrm{C}$ (oil bath set at $80^{\circ} \mathrm{C}$ ) for a duration of 29 h. $8 / 2{ }^{c}$ Determined by GC analysis with tetradecane as standard. ${ }^{d} \mathrm{E} / \mathrm{Z}$ selectivity: $8 / 2$ for entries $3,5-7 ; 7 / 3$ for entries $4,8,10-11 ; 6 / 4$ for entry 9 (determined by GC). ${ }^{e}$ Isolated yields after $\mathrm{SiO}_{2}$ purification. ${ }^{f}$ Determined by GC analysis of 2 (see ESI for details). ${ }^{h}$ Not determined. ${ }^{i}$ Concentration at $0.02 \mathrm{M}$. ${ }^{j}$ Time of reaction is $1 \mathrm{~h}$. 
Despite an increasing thermal stability in comparison with its analogue $\mathrm{Ru}-10^{23}$ (14 days vs 5 hours at $60^{\circ} \mathrm{C}$, see ESI for details), bis(cyclopentylıMes) complex Ru-11a was inefficient in macrocyclisation at either $70^{\circ} \mathrm{C}$ or refluxed condition (entries 1 and $2,<8 \%$ conv.). This lack of reactivity could be explained by the strong binding of the NHC to the metal, which drastically reduces the pre-catalyst initiation rate. ${ }^{25,26}$ Recently, Grubbs and Bertrand described an acidic-mediated protonolysis of the ruthenium-carbene bond to activate bis-carbenic metathesis catalysts. $^{29}$ This prompted us to study the lability of the cyclopentylıMes ligand in presence of a Brönsted acid during the RCM. Pleasantly, by adding $20 \mathrm{~mol} \%$ of $1 \mathrm{M} \mathrm{HCl} / \mathrm{EtOAc}$ solution, catalyst Ru-11a yielded the expected metathesis macrocycle 6 in relatively good isolated yield (80\%, entry 3 ). After hydrogenation, Exaltolide $\mathbf{2}$ was then isolated in quantitative yield and $>99 \%$ purity. Similar good results were obtained by diminishing the amount of acid down to $10 \mathrm{~mol} \%$ (entry 4). At lower catalyst loadings ( 0.1 and $0.05 \mathrm{~mol} \%$ ) in presence of 5 to $2.5 \mathrm{~mol} \%$ of $\mathrm{HCl}$, the catalytic system remained quite efficient as exaltolide $\mathbf{2}$ was formed in 76 and $78 \%$ yield respectively and $>99 \%$ purity (entries 5-6). Interestingly, at higher concentration $(0.02 \mathrm{M})$, the yield of RCM product 6 was only slightly altered, leading to $\mathbf{2}$ in $67 \%$ isolated yield but the purity remained $>99 \%$ (entry 9 ). With the optimized conditions in hands, complexes Ru-11b-e bearing different cycloalkyl- $N$ substituents were also screened, revealing no significant differences in catalytic efficiency (entries 8-11). Nonetheless, complex Ru-11c and Ru-11d bearing respectively a cycloheptyl and cyclooctyl fragment were able to complete the reaction within $1 \mathrm{~h}$ instead of $4 \mathrm{~h}$ (entries 10-11). At last, to complete our study, we next screened other green solvents such as Me-THF, diethylcarbonate (DEC) or isopropanol (Table 3). ${ }^{30}$ The RCM conducted in Me-THF afforded the desired exaltolide $\mathbf{2}$ in $73 \%$ isolated yield and $>99 \%$ purity (entry 1 ). In DEC, our catalyst Ru11a appeared quite inefficient, yielding 2 in extremely low 7\% yield but without any traces of by-products (entry 2 ).

Table 3. Screening of various green solvents for the macrocyclic RCM of hex-5-enyl undec-10-enoate $\mathbf{5}$ catalysed by Ru-11a complex ${ }^{\mathrm{a}}$

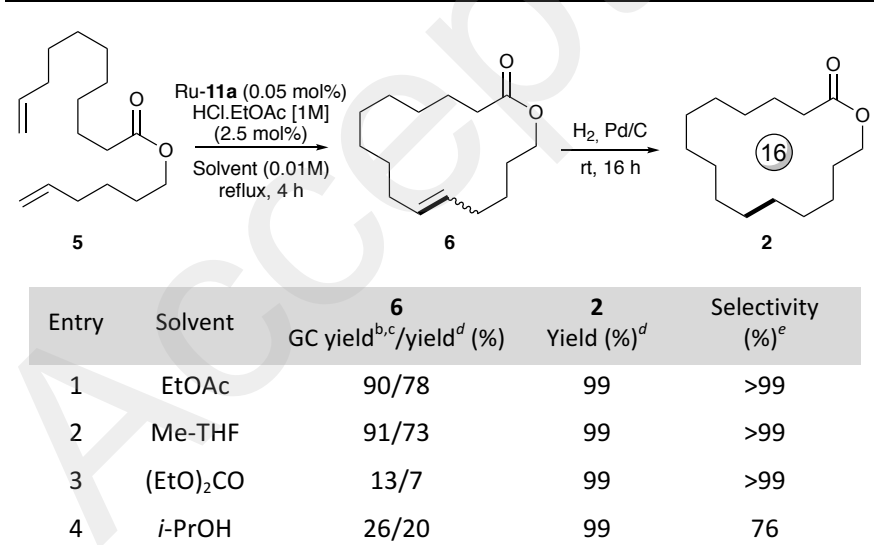

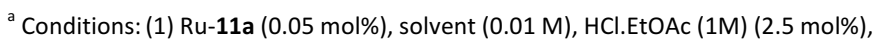
reflux (oil bath set at $\left.110^{\circ} \mathrm{C}\right), 4 \mathrm{~h}$. (2) $\mathrm{H}_{2}(1 \mathrm{~atm}), \mathrm{Pd} / \mathrm{C}(2.5 \mathrm{~mol} \%), \mathrm{rt}, 16 \mathrm{~h}^{b}$ Determined by $\mathrm{GC}$ analysis with tetradecane as standard. ${ }^{c} \mathrm{E} / \mathrm{Z}$ selectivity: $8 / 2$ (determined by GC). ${ }^{d}$ Isolated yields after $\mathrm{SiO}_{2}$ purification. ${ }^{e}$ Determined by GC analysis of $\mathbf{2}$ (see ESI for details).
In alcoholic solvent, the formation of hydrido-Ru species was predominant as $\mathbf{2}$ was isolated in low $20 \%$ yield with a selectivity dropping drastically to $76 \%$.

We then decided to extend the scope of macrocyclic RCM by involving the more promising complex Ru-11a in optimized conditions (EtOAc, $0.01 \mathrm{M}$, reflux, $2.5 \mathrm{~mol} \%$ of $1 \mathrm{M} \mathrm{HCl} /$ EtOAC solution). We started with the synthesis of ambrettolide derivatives 9a and 10a, two attractive artificial fragrances featuring a seventeen-membered macrolactone, which are considered as an alternative musk resource (Scheme 2$).{ }^{31}$ With a catalyst loading of $1 \mathrm{~mol} \%{ }^{32}$ the metathesis cyclised product 9a was isolated in good $70 \%$ yield without any traces of ringcontraction by-products $(>99 \%$ purity). The following hydrogenation of the double-bound afforded the corresponding dihydro-ambrettolide $10 a^{33}$ in quantitative yield (>99\% purity). While similar yield and purity were observed in the formation of the eighteen-membered macrolactone $10 \mathbf{b}^{34}$ (76\% and $>99 \%$ resp.), catalyst Ru-11a appeared less efficient in the RCM leading to the fifteen-membered lactone $10 c^{35}$ in poor $39 \%$ yield but the purity remained excellent.

Scheme 2. Scope of macrocyclic RCM of dienic substrates 8 catalysed by Ru-11a complex leading to the corresponding macrocyclic metathesis product $\mathbf{9}^{\mathrm{a}}$ or related hydrogenated macrocycle $10^{b}$

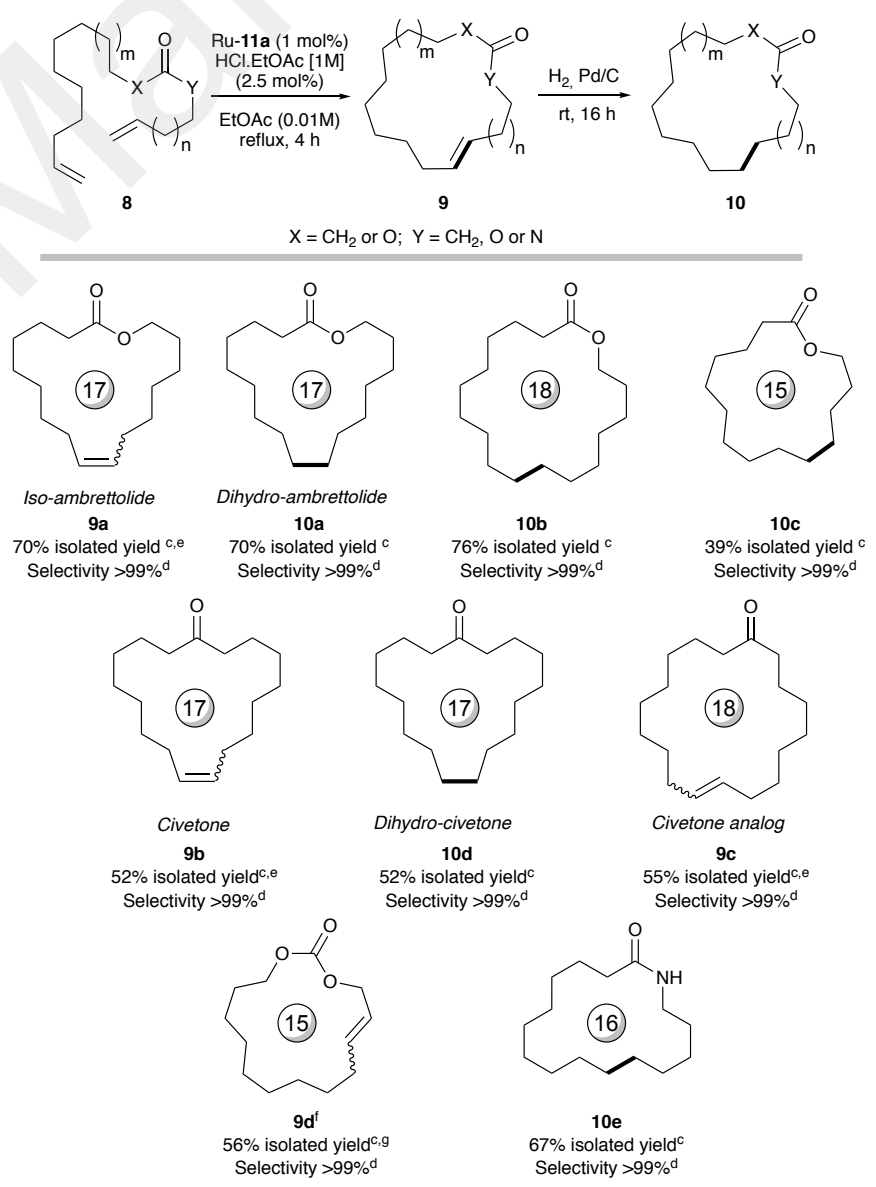

a Conditions: Ru-11a (1 mol\%), AcOEt (0.01 M), 1M HCl.EtOAc (2.5 mol\%), reflux, $4 \mathrm{~h} .{ }^{b}$ Conditions: $\mathrm{H}_{2}(1 \mathrm{~atm}), \mathrm{Pd} / \mathrm{C}(2.5 \mathrm{~mol} \%), \mathrm{rt}, 16 \mathrm{~h} .{ }^{\mathrm{c}}$ Isolated yields after $\mathrm{SiO}_{2}$ purification. ${ }^{d}$ Determined by GC analysis (see ESI for details). ${ }^{e} E / Z$ ratio: $7 / 3 .{ }^{f} 2$ mol\% of catalyst were used (overnight). ${ }^{\mathrm{g}} \mathrm{E} / \mathrm{Z}$ ratio: $9 / 1$ 
This lack of reactivity could be attributed to conformational constraints that disfavour the cyclisation. ${ }^{36}$ The formation of macrocyclic ketones was next studied. The well-known and highly desirable civetone and dihydro-civetone fragrances ${ }^{37} \mathbf{9 b}$ and $10 \mathrm{~d}$ were isolated in pure form with moderate $52 \%$ yields. ${ }^{38}$ A similar moderate $55 \%$ yield was observed with the civetone analog $9 c^{39}$ featuring an eighteen-membered ring. Finally, our methodology was also successful in the formation of macrocyclic carbonate $9 d^{40}$ and macrolactam $10 e^{41}$ which were isolated with 56 and $67 \%$ yields respectively in $>99 \%$ purity.

\section{Conclusions}

To conclude, we developed a set of new rutheniumindenylidene complexes bearing two unsymmetrical unsaturated NHC ligands with a $N$-cycloalkyl moiety. These low-cost catalysts ${ }^{42}$ proved to be highly selective in the macrocyclic ringclosing metathesis reactions performed in ethylacetate solvent at low dilution $(0.01 \mathrm{M})$ without the requirement of benzoquinone derivatives to prevent the isomerisation side reactions. This unprecedented environmentally friendly catalytic process enabled the synthesis of various macrocyclic odorant molecules, which were achieved with a remarkable $>99 \%$ purity and good isolated yields (up to $78 \%$ ). As the isomerization of terminal olefins remains a major obstacle to numerous industrial applications of olefin metathesis, this highly selective technology pave the way to a prosperous future.

\section{Conflicts of interest}

There are no conflicts to declare.

\section{Acknowledgements}

This work was supported by the Association Nationale de la Recherche et de la Technologie and DEMETA company (grant to A.D.; CIFRE N²014/0702), the Région Bretagne (AAP-IMA2105-15006528-BIOFRAGRANCES; grant to G.F.) and the FASO (grant to IC; Z-SELECT). SCR, OB and MM acknowledge the Ecole Nationale Supérieure de Chimie de Rennes (ENSCR) and the Centre National de la Recherche Scientifique (CNRS) for financial supports. Umicore $A G$ \& $C o$ is acknowledged for a generous gift of $M_{1}$ and $M_{2}$ ruthenium complexes.

\section{Notes and references}

1 Selected comprehensive books and reviews on olefin metathesis: a) R. H. Grubbs, A. G. Wenzel, D. J. O'Leary, E. Khosravi, (Eds.) Handbook of Metathesis, $2^{\text {nd }}$ Edition; WileyVCH: Weinheim, Germany, 2015; b) K. Grela (Ed.), Olefin Metathesis: Theory and Pratice, Wiley-VCH: Weinheim, Germany, 2014; c) G. C. Vougioukalakis and R. H. Grubbs, Chem. Rev. 2010, 110, 1746.

2 a) A. Parenty, X. Moreau, G. Niel and J.-M. Campagne, Chem. Rev. 2006, 106, 911; b) A. Parenty, X. Moreau, G. Niel and J.M. Campagne, Chem. Rev. 2013, 113, PR1.
3 H. Clavier, K. Grela, A. Kirschning, M. Mauduit and S. P. Nolan, Angew. Chem. Int. Ed. 2007, 46, 6786.

4 For recent reviews or book chapters dealing with olefin metathesis macrocyclization, see: a) F. Grisi, C. Costabile, A. Grimaldi, C. Viscardi, C. Saturnino and P. Longo, Eur. J. Org. Chem. 2012, 2012, 5928; b) A. Gradillas and J. Perez-Castells in Metathesis in Natural Product Synthesis (Eds.: J. Cossy, S. Arseniyadis, C. Meyer), Wiley-VCH, Weinheim, 2010, p. 149; c) H. Hagiwara, T. Nakamura, N. Okunaka, T. Hoshi and T. Suzuki, Helv. Chim. Acta 2010, 93, 175.

5 a) For instance, see: A. Fürstner and K. Langemann, J. Am. Chem. Soc. 1997, 119, 9130; b) For instance, see: A. Fürstner and G. Seidel, J. Organomet. Chem. 2000, 606, 75.

6 For instance, see: A. Michrowska, P. Wawrzyniak and K. Grela, Eur. J. Org. Chem. 2004, 2004, 2053.

7 Selected reviews on macrocyclic musks: a) A. S. Williams, Synthesis 1999, 1707; b) P. Kraft, J. A. Bajgrowicz, C. Denis and G. Frater, Angew. Chem. Int. Ed. 2000, 39, 2980; For toxicological studies on macrocyclic lactones and ketones, see: c) D. Belsito, D. Bickers, M. Bruze, P. Calow, M. L. Dagli, A. D. Fryer, H. Greim, Y. Miyachi, J. H. Saura and I. G. Sipes, Food and Chemical Toxicology 2011, 49, S219; d) D. Belsito, D. Bickers, M. Bruze, P. Calow, M. L. Dagli, A. D. Fryer, H. Greim, Y. Miyachi, J. H. Saura and I. G. Sipes, Food and Chemical Toxicology 2011, 49, S126.

8 D. McGinty, C. S. Letizia and A. M. Api, Food and Chemical Toxicology 2011, 49, S207.

9 D. McGinty, C. S. Letizia and A. M. Api, Food and Chemical Toxicology 2011, 49, S193.

10 D. McGinty, C. S. Letizia and A. M. Api, Food and Chemical Toxicology 2011, 49, S152.

11 D. McGinty, C. S. Letizia and A. M. Api, Food and Chemical Toxicology 2011, 49, S120.

12 a) S. Hübner, J. G. de Vries and V. Farina, Adv. Synth. Catal. 2016, 358, 3; For a seminal review on olefin metathesis at industrial scale, see b) C. S. Higman, J. A. M. Lummiss and D. E. Fogg, Angew. Chem. Int. Ed. 2016, 55, 3552.

13 a) T. M. Trnka, J. P. Morgan, M. S. Sanford, T. E. Wilhem, M. Scholl, T.-L. Choi, S. Ding, M. W. Day and R. H. Grubbs, J. Am. Chem. Soc. 2003, 125, 2546; b) M. B. Dinger, J. C. Mol, Eur. J. Inorg. Chem. 2003, 2003, 2827; c) S. H. Hong, M. W. Day and R. H. Grubbs, J. Am. Chem. Soc. 2004, 126, 7414; d) B. Schmidt, J. Mol. Catal. A: Chem. 2006, 254, 53; e) N. J. Beach, K. D. Camm and D. E. Fogg, Organometallics 2010, 29, 5450; f) N. J. Beach, J. A. M. Lummins, J. M. Bates and D. E. Fogg, Organometallics 2012, 31, 2349 ; g) S. Manzini, D. J. Nelson, T. Lebl, A. Poater, L. Cavallo, A. M. Z. Slawin and S. P. Nolan, Chem. Commun. 2014, 50, 2205; for mechanistic studies, see: h) I. W. Ashworth, I. H. Hillier, D. J. Nelson, J. M. Percy and M. A. Vincent, Eur. J. Org. Chem. 2012, 2012, 5673.

14 a) A. Fürsner, O. R. Thiel, L. Ackermann, H.-J. Schanz and S. P. Nolan, J. Org. Chem. 2000, 65, 2204; b) D. Bourgeois, A. Pancrazi, S. P. Nolan and J. Prunet, J. Organomet. Chem. 2002, 643-644, 242.

15 a) For the pioneer use of benzoquinones, acids or oxidants to prevent isomerisation during Olefin Metathesis, see: S. H. Hong, D. P. Sanders, C. W. Lee and R. H. Grubbs, J. Am. Chem. Soc. 2005, 127, 17160; For acidic treatments, see also: b) N. Gimeno, P. Formentin, J. H. G. Steinke and R. Vilar, Eur. J. Org. Chem. 2007, 2007, 918.

16 For macrocyclic-RCM involving low catalyst loading, see: a) C. Shu, X. Zeng, M.-H. Hao, X. Wei, N. K. Yee, C. A. Busacca, Z. Han, V. Farina and C. H. Senanayake, Org. Lett. 2008, 10, 1303; b) R. Kadyrov, Chem. Eur. J. 2013, 19, 1002; c) R. Gawin, A. Tracz, M. Chwalba, A. Kozakiewicz, B. Trzaskowski, K. Skowerski, ACS Catal. 2017, 7, 5443.

17 a) M. Jordaan, P. van Helden, C. van Sittert and H. C. M. Vosloo, J. Mol. Catal. A: Chem. 2006, 254, 145 ; see also : B. J. 
van Lierop, J. A. M. Lummins and D. E. Fogg in Olefin Metathesis: Theory and Pratice, Wiley- $\mathrm{VCH}$ : Weinheim, Germany, 2014, p. 85.

18 For instance, see : M. Jordaan and H. C. M. Vosloo, Adv. Synth. Catal. 2007, 349, 184.

19 a) C. W. Lee and R. H. Grubbs, J. Org. Chem. 2001, 66, 2204; b) J. C. Conrad, M. D. Elman, J. A. Duarte Silva, S. Monfette, H. H. Parnas, J. L. Snelgrove and D. E. Fogg, J. Am. Chem. Soc. 2007, 129,1024 ; c) For a special review, see: A. Gradillas and J. Pérez-Castells, Angew. Chem. Int. Ed. 2006, 45, 6086 ; For rare examples of successful macrocyclic RCM at higher concentrations, see: d) M. Raymond, M. Holtz-Mulholland and S. K. Collins, Chem. Eur. J. 2014, 20, 12763; e) A. Sytniczuk, M. Dabrowski, Ł. Banach, M. Urban, S. Czarnocka-Śniadała, M. Milewski, A. Kajetanowicz, and K. Grela J. Am. Chem. Soc. 2018, 140, 8895; see also ref. 16; f) For a recent design of catalysts limiting the formation of oligomers, see: C. S Higman, D. L. Nascimento, B. J. Ireland, S. Audörsch, G. A. Bailey, R. McDonald, D. E. Fogg, J. Am. Chem. Soc. 2018, 140, 1604

20 For previous publications reporting the use of EtOAc as solvent for Ru-based olefin metathesis, see: a) K. Skowerski, J. Bialecki, A. Tracz and T. K. Olszewski, Green Chem. 2014, 16, 1125 ; b) G. A. Abel, S. Viamajala, S. Varanasi and K. Yamamoto, ACS Sustainable Chem. Eng. 2016, 4, 5703. For a previous study reporting AcOEt as a co-solvent, see also ref. 6 and $19 \mathrm{~d}$.

21 Selected commercially available complexes were purchased from Aldrich (Ru-1,2 and Ru-5) or Strem (Ru-2,4 and Ru-8,9). Complex Ru-3: a) M. Scholl, S. Ding, C. W. Lee and R. H. Grubbs, Org. Lett. 1999, 1, 953; Complexes Ru-2,4: b) H. Clavier, C. A. Urbina-Blanco and S. P. Nolan, Organometallics 2009, 28, 2848; Complex Ru-5: c) S. B. Garber, J. S. Kingsbury, B. L. Gray and A. H. Hoveyda, J. Am. Chem. Soc. 2000, 122, 8168; Complex Ru-6: K. Grela, S. Harutyunyan and A. Michrowska, Angew. Chem. Int. Ed. 2002, 41, 4038 Complexes Ru-8,9: d) D. Rix, F. Caijo, I. Laurent, F. Boeda, H. Clavier, S. P. Nolan and M. Mauduit, J. Org. Chem. 2008, 73, 4225; e) H. Clavier, F. Caijo, E. Borré, D. Rix, F. Boeda, S. P. Nolan and M. Mauduit, Eur. J. Org. Chem. 2009, 25, 4254.

22 No or very low conversions were observed below $70^{\circ} \mathrm{C}$ at this catalyst loading.

23 a) M. Rouen, E. Borré, L. Falivene, L. Toupet, M. Berthod, L. Cavallo, H. Olivier-Bourbigou and M. Mauduit, Dalton Trans. 2014, 43, 7044; b) M. Rouen, P. Queval, E. Borré, L. Falivene, A. Poater, M. Berthod, F. Hugues, L. Cavallo, O. Baslé, H. Olivier-Bourbigou and M. Mauduit, ACS Catal. 2016, 6, 7970; c) For a special review on unsymmetrical NHCs-Ru complexes, see: F. B. Hamad, T. Sun, S. Xiao and F. Verpoort, Coord. Chem. Rev. 2013, 257, 2274.

24 The thermal stability of Ru-10 with has been previously studied, see ref. $23 a$.

25 a) T. Weskamp, W. C. Schattenmann, M. Spiegler and W. A. Herrmann, Angew. Chem. Int. Ed. 1998, 38, 2490; b) T. M. Trnka, J. P. Morgan, M. S. Sanford, T. E. Wilhelm, M. Scholl, T.L. Choi, S. Ding, M. W. Day and R. H. Grubbs, J. Am. Chem. Soc. 2003, 125, 2546; c) J. C. Conrad, G. P. A. Yap and D. E. Fogg, Organometallics 2003, 22, 1986; d) W. Zhang, C. Bai, X. Lu, R. He, J. Organomet. Chem. 2007, 692, 3563. e) N. Ledoux, B. Allaert, A. Linden, P. V. D. Voort and F. Verpoort, Organometallics 2007, 26, 1052; For previous mixed (SIMes)( $\mathrm{NHC}) \mathrm{Cl}_{2} \mathrm{Ru}$-indenylidene complexes, see: f) $\mathrm{X}$. Bantreil, R. A. M. Randall, A. M. Z. Slawin and S. P. Nolan, Organometallics 2010, 29, 3007; g) L. H. Peeck and H. Plenio, Organometallics 2010, 29, 2761.

26 M. Rouen, P. Queval, L. Falivene, J. Allard, L. Toupet, C. Crévisy, F. Caijo, O. Baslé, L. Cavallo and M. Mauduit, Chem. Eur. J. 2014, 20, 13716.
27 a) P. Queval, C. Jahier, M. Rouen, J.-C. Legeay, I. Artur, P. Querard, L. Toupet, C. Crévisy, L. Cavallo, O. Baslé and M. Mauduit, Angew. Chem. Int. Ed. 2013, 52, 14103; b) R. Tarrieu, A. Dumas, J. Thongpaen, T. Vives, T. Roisnel, V. Dorcet, C. Crévisy, O. Baslé and Marc Mauduit, J. Org. Chem. 2017, 82, 1880.

28 CCDC-1051157 (Ru-11b) ; CCDC-907749 (Ru-11c); CCDC906510 (Ru-11d) ; CCDC-870531 (Ru-11e) contain the supplementary crystallographic data for this paper. These data can be obtained free of charge from The Cambridge Crystallographic Data Centre via: www.ccdc.cam. ac.uk/data request/cif.

29 B. K. Keitz, J. Bouffard, G. Bertrand and R. H. Grubbs, J. Am. Chem. Soc. 2011, 133, 8498; see also ref. 26.

30 C. Bruneau and C. Fischmeister in Olefin Metathesis: Theory and Pratice, Wiley-VCH: Weinheim, Germany, 2014, p. 523.

31 For a previous synthesis of (9E)-Isoambrettolide 9a (lactonisation): I. Shiina and M. Hashizume, Tetrahedron 2006, 62, 7934.

32 At 0.1 mol\% of catalyst loading, a similar yield is observed.

33 a) D. McGinty, C. S. Letizia and A. M. Api, Food and Chemical Toxicology 2011, 49, S183; b) For a previous synthesis of Dihydro-ambrettolide 10a: J. A. Morales-Serna, E. Sánchez, R. Velázquez, J. Bernal, E. García-Ríos, R. Gaviño, G. Negrón-Silva and J. Cárdenas, Org. Biomol. Chem. 2010, 8, 4940.

34 For a previous synthesis of $\mathbf{1 0 b}$ (radical photocyclization), see: S. K. Nishikawa, Y. Yoshimi, K. Maeda, T. Morita, I. Takahashi, T. Itou, S. Inagaki and M. Hatanaka, J. Org. Chem. 2013, 78, 582.

35 For a previous synthesis of macrolactone 10c (lactonisation), see: Y.-S. Hon, Y.-C. Wong, C.-P. Chang and C.-H. Hsieh, Tetrahedron 2007, 63, 11325.

36 V. Martí-Centelles, M. D. Pandey, M. I. Burguete and S. V. Luis, Chem. Rev. 2015, 115, 8736.

37 For a previous synthesis of civetone $\mathbf{9 b}$ and dihydro-civetone 10d: a) R. Callejo, M. J. Corr, M. Yang, M. Wang, D. B. Cordes, A. M. Z. Slawin and D. O'Hagan. Chem. Eur. J. 2016, 22, 8137; b) For a stereoselective synthesis of Z-civetone, see: L. E. Rosebrugh, M. B. Herbert, V. M. Marx, B. K. Keitz and R. H. Grubbs, J. Am. Chem. Soc. 2013, 135, 1276.

38 At $0.25 \mathrm{~mol} \%$ of catalyst loading, the yield slightly dropped to reach $40 \%$ of 9 b.

39 For a previous synthesis of civetone analog 9c, see: A.T. Blomquist and J. Wolinsky, J. Am. Chem. Soc. 1965, 77, 5423.

40 For a previous synthesis of macrocyclic carbonate $9 d$, see: A. Michrowska, P. Wawrzyniak and K. Grela, Eur. J. Org. Chem. 2004, 2053.

41 For a previous synthesis of macrolactam 10e, see: D. E. Williams, K. S. Craig, B. Patrick, L. M. McHardy, R. van Soest, M. Roberge and R. J. Andersen, J. Org. Chem. 2002, 67, 245.

42 As complexes Ru-11 incorporate NHC ligands available through a one-step process involving cheap reagents, they could be considered as low-cost catalysts, see ref. 27 . 